\title{
Molecular Identification of Mycobacterium tuberculosis and Analysis of Its Resistance to Rifampin in Sputa From Tuberculosis Suspected Patients
}

\author{
M. Syaifudin \\ Center for Radiation Safety and Metrology Technology, National Nuclear Energy Agency \\ Jl. Cinere Pasar Jum'at PO BOX 7043 JKSKL Jakarta, Indonesia
}

\section{ARTICLE INFO}

Article history:

Received 27 February 2009

Received in revised form 28 August 2010

Accepted 30 August 2010

\section{Keywords:}

Mycobacterium tuberculosis

Resistance

Rifampin

Mutation

RpoB

PCR-SSCP

\begin{abstract}
A B S T R A C T
An accurate identification of different species of Mycobacterium provides to allow appropriate treatment for Mycobacterium tuberculosis infection. Beside that, drug resistance of $M$. tuberculosis strains to rifampin is not clearly understood in contributing to the spread of tuberculosis in Indonesia. To assess the molecular mechanism of rifampin resistance, a number of clinical specimens of M. tuberculosis were analyzed their molecular nature of a part of the $r p o B$ gene using polymerase chain reaction-single strand conformation polymorphism (PCR-SSCP) methods. DNA's extracted from sputum samples were amplified and ${ }^{32} \mathrm{P}$-labeled by PCR with the specific primers and the product was analyzed their mutation conferring resistance by MDE gel electrophoresis. Of the 70 specimens tested, 57 specimens were positive for M. tuberculosis organism only, three specimens contained a mixture of $M$. tuberculosis and non tuberculosis mycobacteria (NTM), and 10 specimens were negative approved by Duplex PCR. Of these sixty DNA positive samples (thus the sensitivity of PCR was $85.71 \%$ ), $5(8.3 \%)$ of them suspected to contain mutations in $r p o B$ which were associated with rifampin resistance. Even though the frequency of mutation was low, the results from our study clearly indicate that the molecular mechanism of rifampin resistance in $M$. tuberculosis isolates from Indonesia involves alterations in the $r p o B$ gene. Molecular diagnosis by PCR which is fast and easy to perform is useful for early and rapid detection of TB in sputum specimen.
\end{abstract}

(C) 2010 Atom Indonesia. All rights reserved

\section{INTRODUCTION}

Tuberculosis (TB) is the leading cause of mortality in adults due to an infectious agent called M. tuberculosis and accounts for $26 \%$ of all preventable adult deaths globally [1]. TB has also emerged as a major public health problem in Indonesia. Therefore, it should be the first priority disease requiring proper treatment and research efforts. The prevalence of TB was $0.29 \%$ ( $0.24 \%$ on the basis of positive sputum smears), and $5.6 \%$ of the world's 7.5 million new cases of TB in 1990 $[2,3]$. With nearly 557,000 TB cases where 175,000 deaths annually and an incidence rate of 115 new sputum smear positive cases per 100,000 population by 2002 , TB ranks second among the leading causes of death in this country [4] and the first rank among the communicable and infectious diseases.

\footnotetext{
* Corresponding author.

E-mail address: mukh_syaifudin@batan.go.id (M. Syaifudin)
}

Therefore, a rapid detection and treatment of cases is urgently needed and currently the key strategy to control the spread of TB. However, the effectiveness of this control strategy is being limited because of the emergence and spread of drug-resistant TB, particularly multidrug-resistance tuberculosis (MDR-TB) which indicating the resistance to at least isoniazid and rifampin [5]. This resistance results from inadequate treatment, but often because of an irregular drug supply, inappropriate regimens, or poor compliance. Although there is also growing concern about the increasing incidence of MDR-TB which is considered a major threat in developing countries, its prevalence in Indonesia was noted to be as low as $0.7 \%$ according to World Health Organization (WHO) Mission Report 2004 (PPM DOTS in Indonesia: A Strategy for action).

Species identification of Mycobacterium can be achieved by biochemical and conventional tests but it has proven to be difficult to use these tests because of time-consuming and often incorrect 
identification [6]. In order to overcome such difficulties, several molecular tests supported by the availability of genome sequencing data have been developed and many genes are the targets for molecular technique-based species identification such as Duplex PCR [7]. Substantial progress has been made in understanding of the molecular basis of M. tuberculosis drug resistance in the last two decade [8]. Understanding the genetic events that lead to drug resistance in clinical $M$. tuberculosis isolates is important for the development of genetic assays, elucidation of the mechanisms of action of antimicrobial agents, and the design of novel antibiotics that are active against drug-resistant strains [9]. Drug resistant strains emerge when chemotherapy is intermittent or otherwise inadequate. Several factors influence the degree of success of treatment programs including duration and complexity of therapy, ease of healthcare access, treatment cost, patient adherence, and drug side effects [10].

Rifampin is an approved anti-mycobacterial drug that is a standard component of combination regimens and first line medication for treating TB. The highly effective bactericidal action of this drug against $M$. tuberculosis has made it a key component of the initial anti-tuberculous regimen. Analysis of approximately 500 rifampin strains from global sources has found that $96 \%$ of rifampin resistant clinical isolates of $M$. tuberculosis have mutations in the 81-bp core region of $r p o B$, a kind of housekeeping gene, which encodes the beta-subunit of RNA polymerase $[8,11]$ and apparently blocks the entry of the first nucleotide which is necessary to activate the polymerase, thereby blocking mRNA synthesis. Mostly missense mutations caused rifampin resistance were found in codons 513, 526, or 531 of $r p o B$, whereas amino acid changes at position 514 or 533 usually result in low levels of rifampin resistance [8]. It is estimated that $90 \%$ of rifampin-resistant isolates in some areas are also resistant to isoniazid, making rifampin resistance a useful surrogate marker for multidrug resistance and indicating that second and third line drugs to which these isolates are susceptible are urgently required $[12,13]$. It has been found to have greater bactericidal effect against $M$. tuberculosis than other anti-tuberculosis drugs, and it has largely replaced isoniazid as one of the front-line drugs used to treat the disease, especially when isoniazid resistance is indicated.

Delineation of the molecular mechanisms of antimicrobial agent resistance has resulted in the development and application of several Polymerase Chain Reaction (PCR)-based strategies designed to rapidly detect mutations associated with resistance
[14] such as duplex [15], multiplex [16,17], real time $[18,19]$ or nested PCR $[20,21]$ and PCR-enzyme linked immunosorbent assay (ELISA) [22]. Genomic detection by PCR has been reported to be a rapid, simple, and very sensitive tool for detecting mycobacteria in clinical samples. This paper represents the results of molecular identification and analysis for the detection of drug resistance in sputum DNA isolated from TB patient in Jakarta and is theoretically able to provide a same-day diagnosis from clinical samples.

\section{EXPERIMENTAL METHODS}

\section{Clinical Samples}

Seventy sputum specimens were obtained in 2003-2005 from individuals (55 women and 15 men; mean age \pm standard deviation, 67 years \pm 15.2 years) who were out patients in Health Center for Lung Diseases or Indonesian Tuberculosis Eradication Association (Perkumpulan Pemberantasan Tuberkulosis Indonesia, PPTI), a non-governmental organization, located at Jl. Sultan Iskandar Muda 66A in South Jakarta (50 samples) and Lung Disease Health Center (Balai Pengobatan Penyakit Paru-paru, BP4) located at Jl. Prof. dr. Suharso 28 Surakarta Central Java (20 samples). These patients were suspected of having tuberculosis, with positive response to acid fast bacilli (AFB) by Ziehl-Neelsen staining. Two to five milliliters of expectorated early-morning sputa was transferred in sterile cups to the laboratory, where a direct smear was prepared. If any of the samples contained $>3$ bacilli it was categorized as AFB positive. For decontamination and homogenization, sputum samples were added with equal volume of $4 \% \mathrm{NaOH}$ and disrupt the cell wall by rotary shaking at speed 500 for 20 min. After washing with saline twice, pellet was used for DNA extraction.

\section{Extraction of Mycobacterial DNA from Sputum Samples}

DNA isolation from clinical specimens was performed as previously described [7]. Five hundred microlitter of sputum specimens were digested and decontaminated with the same volume of $\mathrm{N}$-acetyl L-cysteine $\mathrm{NaOH}-\mathrm{Na}$ citrate (NALC) solution. One part of NALC pellets was inoculated onto Löwenstein-Jensen slants and incubated for up to 6-8 weeks at $37^{\circ} \mathrm{C}$ and other part was for extraction of DNA. All procedures to inoculate and extract DNA were performed in a biological safety cabinet. Decontaminated specimen was transferred to a 
sterile microcentrifuge tube and shaked in rotary shaker for $20 \mathrm{~min}$. Samples were then centrifuged, and the pellet was washed twice with sterile distilled water. After recentrifugation the pellet was resuspended in $500 \mu \mathrm{l}$ of deinozed water containing $5 \mu \mathrm{l}$ of proteinase- $\mathrm{K}(0.25 \mathrm{mg} / \mathrm{ml})$ and incubated at $56^{\circ} \mathrm{C}$ for $1 \mathrm{~h}$ followed by boiling for $10 \mathrm{~min}$. Samples were then centrifuged, and the supernatant was used for PCR amplification. In order to check for possible contamination, a negative control consisting of all the reagents except target DNA was run in parallel with the samples in every set of amplification reactions.

\section{Duplex PCR}

The Duplex PCR for differentiation of M. tuberculosis and MOTT was done with primer sets of $r p o B$ constructed from the specific nucleotides of the $M$. tuberculosis or NTM strains located at the $3^{\prime}$-hydroxyl end of each primer, as previously reported $[7,15]$. The developed Tbc1 (5'-CGT ACG GTC GGC GAG CTG ATC CAA3')-TbcR5 (5'-C CAC CAG TCG GCG CTT GTG GGT CAA-3') and M5 (5'-G GAG CGG ATG ACC ACC CAG GAC GTC-3')-RM3 (5'-CAG CGG GTT GTT CTG GTC CAT GAA C-3') primer sets amplify a 235-bp DNA sequence from the M. tuberculosis complex and a 136-bp DNA sequence from NTM, respectively. Primers $(10 \mathrm{pmol}$ of Tbc1-TbR5 and 20 pmol of M5-RM3) and $3 \mu 1$ of bacterial DNA were added to a PCR mixture tube (AccuPower PCR PreMix; Bioneer, Daejeon, Korea) containing $2 \mathrm{U}$ of $\mathrm{Taq}$ polymerase, $250 \mu \mathrm{M}$ each deoxynucleoside triphosphate, $10 \mathrm{mM}$ Tris- $\mathrm{HCl}$ (pH 8.3), and $1.5 \mathrm{mM} \mathrm{MgCl}$, and water was added to a final volume of $20 \mu \mathrm{l}$ per reaction mixture. PCR was performed with an initial denaturation of $95^{\circ} \mathrm{C}$ for $5 \mathrm{~min}, 30$ cycles of amplification $\left(30 \mathrm{~s}\right.$ at $95^{\circ} \mathrm{C}$, $30 \mathrm{~s}$ at $74^{\circ} \mathrm{C}, 4 \mathrm{~min}$ at $74^{\circ} \mathrm{C}$ ), and a final elongation at $74^{\circ} \mathrm{C}$ for $5 \mathrm{~min}$ (BioRad Gene Cycler, Japan). The PCR products were analyzed by agarose gel (1.5\%) electrophoresis.

\section{Detection of Amplified Products}

Amplified products were resolved electrophoretically on $1.5 \%$ agarose (Sigma Aldrich, Inc.) made up in 1.0X TAE (Tris-Acetate-EDTA) containing ethidium bromide $(0.5 \mu \mathrm{g} / \mathrm{ml})$ and visualised on $260 \mathrm{~nm}$ wavelength UV transilluminator (Chromato-Vue San Gabriel CA, Model TM36) completed with Foto/Analyst Mini Visionary Fotodyne Inc., Model No. 69 and Mitsubishi Video copy processor P67UA.

\section{Nested PCR}

One tube nested PCR was done with TB1 (5'-ACG TGG AGG CGA TCA CAC CGC AGA CGT-3') and TB2 (5'-TGC ACG TCG CGG ACC TCC AGC CCG GCA-3') as outer primers and TB3 (5'-TCG CCG CGA TCA AGG AGT TCT TC-3') and TR8 (TGC ACG TCG CGG ACC TCC-3') as inner primers as described in previous report $[7,23]$. PCR was performed in a tube (AccuPower PCR PreMix; Bioneer) containing $2 \mathrm{U}$ of $\mathrm{Taq}$ polymerase, $10 \mathrm{mM}$ Tris- $\mathrm{HCl}(\mathrm{pH} 8.3)$, and $1.5 \mathrm{mM} \mathrm{MgCl}$, and 20 pmol of each TB1 and TB2 primers and $1.5 \mathrm{pmol}$ of each TB3 and TB8 primers and then the volume was adjusted to $20 \mu \mathrm{l}$. One microlitter $(0.1 \mu \mathrm{Ci})$ of $\left[\alpha-{ }^{32} \mathrm{P}\right] \mathrm{dCTP}$ (Amersham International) was added to the reaction mixture and was subjected to preheating at $94^{\circ} \mathrm{C}$ for 5 minutes and then followed by 15 cycles of first round amplification $(30 \mathrm{~s}$ at $94^{\circ} \mathrm{C}, 1 \mathrm{~min}$ at $82^{\circ} \mathrm{C}$ ) followed by the second amplification which was performed in 30 cycles (30 s at $94^{\circ} \mathrm{C}, 1 \mathrm{~min}$ at $72^{\circ} \mathrm{C}$ ) followed by a 5 -min extension at $72^{\circ} \mathrm{C}$ in a BioRad Thermalcycler. The Rif $^{\mathrm{r}}$ reference strain (H37Rv ATCC 35838) that had a mutation in codon $531(\mathrm{C} \rightarrow \mathrm{T})$ was used as positive control.

\section{Single-strand Conformation Polymorphism (SSCP)}

SSCP technique was used to localize the mutation. Six microlitter of the radioactively labelled nested PCR product was mixed with $6 \mu \mathrm{l}$ of SSCP loading dye (95\% formamide (Biorad), 0.5M EDTA and $0.05 \%$ Bromophenol blue (Biorad) denaturants). The samples were denatured at $95^{\circ} \mathrm{C}$ for 4 minutes and snap cooled on ice and loaded on the 0.5X Mutation Detection Enhancement (MDE) gel (BMA, Rockland, ME, USA). Electrophoresis was run at constant watt at room temperature (in an air conditioned room at $20-25^{\circ} \mathrm{C}$ ) for $6-7$ hours. The MDE gels were transferred to Whatman filter paper and covered with saran wrap. They were then dried in a gel drier (Rapid Dry, Atto, Japan) for 0.45-1 hour, exposed to $x$ ray film (AGFA) in a x-ray cassette at $-80^{\circ} \mathrm{C}$ for $24-72$ hours, and developed with Fuji Medical Processor 1200 Japan [24].

\section{RESULTS AND DISCUSSION}

For identification of M. tuberculosis, a novel duplex PCR method that can amplify the 235- and 136-bp rpoB DNAs of $M$. tuberculosis and NTM, respectively, with two different sets of primers was used to differentially identify 70 clinical isolates of 
mycobacteria from tuberculosis patients from Jakarta and Surakarta areas of Indonesia in a singlestep assay. Showing 100\% sensitivity and specificity, the duplex PCR method could clearly differentiate $M$. tuberculosis complex and NTM strains in term of size. Of the 70 specimens suspected containing $M$. tuberculosis, 57 specimens were positive for $M$. tuberculosis organism by duplex PCR and 10 others were negative. Three specimens contained a mixture of $M$. tuberculosis dan NTM approved by two bands seen in agarose gel (Fig. 1). Therefore, these patients should be treated with different regimen and may need a special condition of culture for subsequent studies. Fig. 1 shows the results of electrophoresis of 8 PCRamplified samples. Of the 8 amplified products, 5 showed the electrophoretic pattern of 1 DNA band of $235 \mathrm{bp}$, which corresponded to M. tuberculosis. The amplified size of 3 samples were 136 bp for NTM. The 3 other amplified products showed an electrophoretic pattern of 2 bands of $235 \mathrm{bp}$ for M. tuberculosis and 136 bp for NTM. The negative controls consistently failed to yield detectable PCR products, whereas the positive controls always gave the expected PCR products.

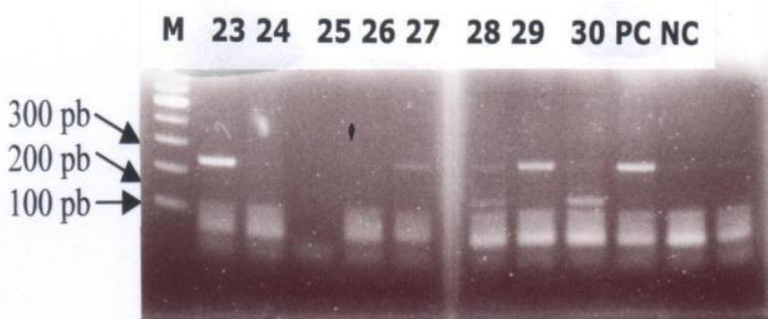

Fig. 1. Results of identification of $M$.tuberculosis with Duplex PCR that showing mixture of $M$. tuberculosis and NTM in samples no. 28 and 30 . No any species was detected in samples no. 24,25 and 26. M, PC and $\mathrm{NC}$ represent marker $100 \mathrm{bp}$, positive control and negative control, respectively.

Analysis of rpoB mutation with SSCP technique identified the alteration of mobility shift of DNA band in acrylamide gel conferring mutations in the 81-bp core region of the $r p o B$ gene in five $(8.33 \%)$ clinical isolates of $M$. tuberculosis complex included in the study. The results of SSCPautoradiography analysis were presented in Fig. 2 that showing all five samples with pattern of DNA mobility shift similar with resistant reference strain (R) and different with susceptible strain (S). Genotypic evidence of rifampin resistance in 60 of 70 AFB-confirmed, rifampin-resistant isolates was obtained by PCR, yielding specificity for the assay of $85.71 \%$. These results demonstrate the feasibility of using a PCR-based assay directly on sputum specimens for simultaneous detection of M. tuberculosis and rifampin resistance, and they suggest that patients with smear-positive, untreated tuberculosis and those presenting with suspected drug-resistant tuberculosis are the most appropriate groups for testing by PCR.

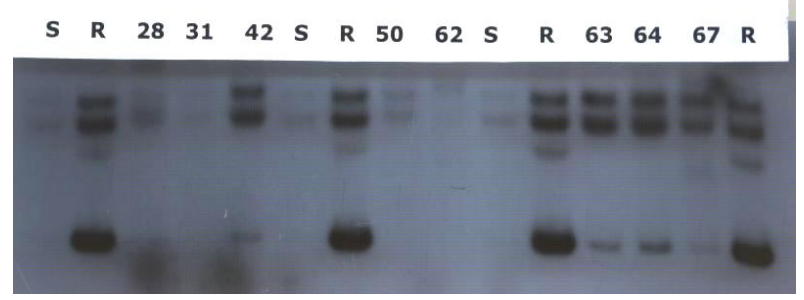

Fig. 2. Results of electrophoresis with MDE gel for SSCP analysis of the $r p o B$ gene. The resistance to the RIF was seen in samples no. 28, 42, 63, 64 and 67. S is standard sample for susceptible strain and $\mathrm{R}$ is resistant strain. Electrophoresis was done for 8 hours in room temperature and 40.5 hours exposure of autoradiography.

Despite a highly effective chemotherapy, tuberculosis currently kills more people than any other infectious disease and is still a leading killer of young adults worldwide mainly in developing countries. Resurgence of tuberculosis in the early 1990s has successfully been controlled and largely reduced in Indonesia by implementing the DOTS strategy adopted from WHO by National Movement Program on TB (Gerdunas TB) where 98\% of the country's population had been covered by year 2001 [25]. However, the risk of contracting this disease is being resurgent when economical crisis was weaving in 1998. With the increase in drug-resistant $M$. tuberculosis strains, the need for an improved genetic elucidation has become an international priority [10]. In Indonesia, however, the frequency of the mutations that conferring the resistance of Mycobacterium to the TB drugs has not been fully investigated, moreover with nuclear technique of which it was proven to be 8-10 times more sensitive compared to Giemsa or Silver staining. Furthermore, not many studies have used sputum specimens to detect these point mutations due to limited facility and fund. Beside that, the results obtained in our study must be validated with a great number of RMP-resistant strains for different region in Indonesia. Unfortunately, it was not possible to draw any conclusions for RMP because of the low number of sample analyzed compared to the extremely high burden of TB patients.

Although rifampin is a key drug in tuberculosis treatment, its molecular mechanism causing resistance is little known in countries endemic for tuberculosis such as Indonesia. Therefore, a rapid and accurate diagnosis and effective treatment of tuberculosis are cornerstones in the prevention of this worldwide epidemic. Nested 
PCR is one of such tools. Gene amplification techniques for the diagnosis of M. tuberculosis in respiratory specimens like sputum, along with traditional smear and culture methods, despite their limitations, have attracted considerable interest in developing countries with all problems behind [18]. Because of the widespread use, it has caused the rifampin-resistant strains, threatening its usefulness in treating mycobacterial diseases. Previous technique for monitoring of suspected cases of rifampin resistance was the extremely long susceptibility test. Improvements are needed to yield accurate analysis in the shorter time and for small bacillary number materials. DNA diagnostic assays have the potential to provide rapid analysis of rifampin resistance in mycobacteria because of their high degree of sensitivity and specificity and the fact that they do not rely on in vitro growth for results. Shortening the time between diagnosis and the onset of effective therapy should decrease the number of patients. Therefore, rapid and sensitive detection of mutations at the $r p o B$ gene of $M$. tuberculosis would be of great importance for proper management of TB patients and control of multi-drug resistant TB. PCR-SSCP using both radioisotopic and nonradioisotopic methods have been widely used for detecting such mutations [26,27]. Radioactive labeling techniques are of major importance in the study of DNA examinations in bacteria. The radioisotope-based PCR-SSCP with an 8 to 10 -fold higher sensitivity over the color-based method such as silver staining would be of great advantage in applying such technology directly to clinical samples.

In microbiology, DNA amplification using PCR has allowed great progress to be made in the rapid and accurate diagnosis of infections due to organisms that are not cultivable by in vitro means, that require complex media or cell cultures and prolonged incubation times, or for which culture is too insensitive. Amplification techniques for the diagnosis of tuberculosis have attracted considerable interest, particularly with the hope of shortening the time required to detect and identify $M$. tuberculosis in respiratory specimens [28]. However, despite numerous reports in the literature [29-32], amplification techniques do not yet have an established role in the laboratory for tuberculosis diagnosis, nor have they replaced traditional techniques, in contrast to diagnostic modalities for other pathogens, like Chlamydia or Mycoplasma [28]. PCR-based assays can provide rapid identification of pathogens by selective amplification of species- or strain-specific regions of the bacterial genome [33]. Isolating template DNA from sputum that is free of PCR inhibitors is an essential component of any PCR assay and the method should be rapid and simple to use but a reliable process for cell lysis is always required. Most other PCR-based methods detect only the presence of a mutation, not the actual substitution in the $r p o B$ gene. This limits our ability to estimate the level of resistance to rifampin and may lead to falsepositive and false-negative reports. Nevertheless, there is a need to quantify antibiotic resistance in order to manage and control MDR-TB.

We found a low frequency of resistance of Mycobacterium tuberculosis to rifampin. This is in accordance to other drug susceptibility testing that demonstrated a low rate of resistance to drugs used for TB treatment in Indonesia. Low-frequency of genetic alterations in $r p o B$ gene region associated with in-vitro resistance to rifampin and rifabutin was also found by others [34-36]. Moreover, the clinical implications and the diagnostic utility of their detection remain controversial. Although several different molecular techniques such as heteroduplex analysis, line probe assay, and PCR-SSCP have been used for analysis of $r p o B$ gene mutations, these techniques were limited in that only the most frequent types of mutations were included. In this research, the $r р о B$ gene of clinical isolates of $M$. tuberculosis was amplified to assess the efficiency of PCR amplification from clinical isolates using radioisotopic nuclides, rather than non radioisotopic nuclides. It was known that the efficiency of PCR for amplifying the $r p o B$ gene from clinical strains of M. tuberculosis was slightly higher than that of ethidium bromide staining (data not shown), indicating that radioisotopic nuclides did not interfere with amplification efficiency of PCR. Moreover, the major limiting factor of successful detection of mutation of the $r p o B$ gene from clinical samples will be sensitivity of PCR-SSCP. Therefore, the radioisotope-based PCR-SSCP with an 2 to 3-fold, or even 8-10 times as results of Lee, H. et al. [26], higher sensitivity over the ethidium bromide staining method would be of great advantage in applying such technology directly to clinical samples. Our study did not find any higher sensitivity of radioactive labeled DNA compared to conventional ethidium bromide staining (data not shown).

We have shown an association between mutations in a short segment of the rpoB gene and phenotypic rifampin resistance in five M. tuberculosis isolates. It has been widely known that rifampin resistance in $M$. tuberculosis has been shown to be predominantly due to mutations in an 81-bp region of the $r p o B$ gene designated the rifampin resistance-determining region. Interestingly, the substituted amino acids in our 
rifampin-resistant strains reflected the most commonly found residues in clinical rifampinresistant $M$. tuberculosis isolates. In view of recent studies using $r p o B$ gene sequencing to determine mycobacterial species [37], analysis of this gene has the potential to provide rapid information on both species and rifampin susceptibility of organisms such as M. kansasii and M. tuberculosis. A mutation in Hys526Tyr of rpoB gene was found in Indonesian sample analyzed by Hirano et al with reverse hybridization-based line probe assay (INNO-LiPA Rif TB) [38]. This kind of mutation in $r p o B$ gene (Hys526Tyr) was also found in Indonesian samples (5 out of 30 samples) analyzed by Maeda et al. [39]. One mutation resulted in Asp516Asn was also found in these samples.

We and others have shown that mutations in the RNA polymerase $(r p o B)$ gene of M. tuberculosis are associated with rifampin resistance. Several investigators have reported on the utility of the PCR-SSCP method for identifying mutations in genes of $M$. tuberculosis associated with resistance to rifampin with quite distinct results due to several factors $[7,11-13,15,17,19,20]$. For this method, mobility shifts in high-resolution nondenaturing polyacrylamide gels are discernible for single-stranded mutated DNA versus wild-type DNA. After amplification of the target nucleic acid by PCR, it is denatured to a single strand and then electrophoresed. Mutations are inferred by the appearance of bands at positions different to those observed with the wild-type strain (Fig. 2). We have determined that the size of the PCR product is a critical factor for resolving differences of the denatured single-stranded DNA. In our hands, the optimal PCR product is in the range of 310 to 320 bp. A drawback of the conventional SSCP method has been the use of radioactivity for identifying amplification products as we did in this report.

Screening for mutations prior to sequencing can reduce the time and costs of identifying mutations. When the DNA sequence is known, the technique of detecting mutations as SSCP is a convenient method of screening for possible mutations due to its technical simplicity and relatively high sensitivity for the detection of mutations. It has the ability of detecting a single base change, and has been applied to a big number of genes. It must be considered that detection and amplification of mutations in genes in a cheap and $100 \%$ effective manner is a major objective in modern molecular genetics. SSCP is a reproducible, rapid and quite simple method for the detection of deletions, insertions, and rearrangements in PCR amplified DNA. SSCP identifies variation by distinguishing changes in the secondary structure of a single-stranded PCR product in response to changes in nucleotide sequence or single nucleotide polymorphism (SNP). It has been used successfully for detecting unknown mutations and for screening known mutations. The technique is simple and fits well in any laboratory where sequencing or genotyping is performed. SSCP has traditionally been performed on standard polyacrylamide gels, using P-32 isotope and autoradiography or ethidium bromide staining. SSCP is most useful for amplicons 130 to $250 \mathrm{bp}$ long. The optimal PCR fragment size for SSCP is $150 \mathrm{bp}$ and that the percentage of mutations detected dropped with increasing fragment size and was compromised with very small fragments. Sensitivity can vary among laboratories and loci, but published reports have shown it to be between $70 \%$ and $100 \%$ for fragments in this size range $[40,41]$. Some factors contributing to the sensitivity of mutation detection including choice of gel matrix, electrophoretic conditions, presence of neutral additives, fragment size, and $\mathrm{G}+\mathrm{C}$ content. A major advantage of SSCP is that many individual PCR products may be screen for variation simultaneously and much more efficient method of obtaining information about levels of polymorphisms within anonymous nuclear loci. In this study, we used PCR and followed by SSCP where the abnormal band on a nondenaturing polyacrylamide gel was seen. MDE gel has advantages over conventional polyacrylamide in resolving subtle mobility difference in DNA.

\section{CONCLUSIONS}

In conclusion, of the 70 specimens tested, 57 specimens were positive for $M$. tuberculosis organism only and three specimens contained a mixture of $M$. tuberculosis and non tuberculosis mycobacteria (NTM) approved by Duplex PCR. of these sixty DNA positive samples (thus the sensitivity of PCR was $85.71 \%), 5(8.3 \%)$ of them suspected to contain mutations in $r p o B$ which were associated with rifampin resistance. Even though low frequency, the results from our study clearly indicate that the molecular mechanism of rifampin resistance in $M$. tuberculosis isolates from Indonesia involves alterations in the $r p o B$ gene. Molecular diagnosis by PCR which is fast and easy to perform is useful for early and rapid detection of TB in sputum specimen. It suggested that PCR analysis should be developed for relevant MDR-TB target genes in a large number of samples. Cumulative data concerning the relationship between the phenotype, clinical response, and type and position of mutations are recommended to facilitate the rapid response 
required to limit the extent and severity of MDR-TB transmission and infection. It have been developed a highly sensitive and specific nested PCR capable of detecting $M$. tuberculosis DNA in sputum specimens which is a most available sample taken from patients.

\section{REFERENCES}

1. M. Raviglione, D. Sinder and A. Kochi, JAMA 273 (1995) 220.

2. Anonymous, Proposed national health research priorities: The View of National Institute of Health Research and Development (NIHRD), Ministry of Health, Republic of Indonesia, Jakarta, Indonesia (1999).

3. E. Karyadi, W. Schultink, R.H.H. Nelwan, R. Gross, Z. Amin, W.M.V. Dolmans, J.W.M. van der Meer, J.G.A.J. Hautvast and C.E. West, Journal of Nutrition 130 (2000) 2953.

4. Household Health Survey, Department of Health RI, Jakarta, Indonesia (1995).

5. M.D. Iseman and L.A. Madsen, Clinics in Chest Medicine 10 (1992) 341.

6. H. Lee, H.E. Bang, G.H. Bai and S.N. Cho, Journal of Clinical Microbiology 41 (5) (2003) 2213.

7. B.J. Kim, K.H. Lee, B.N. Park, S.J. Kim, E.M. Park, Y.G. Park, G.H. Bai, S. J. Kim and Y.H. Kook, Journal of Clinical Microbiology 39 (2001) 2610.

8. J. Musser, Clinical Microbiology Review 8 (1995) 496.

9. A.S. Piatek, A. Telenti, M.R. Murray, H. ElHajj, W.R. Jacobs Jr., F.R. Kramer and D. Alland, Antimicrobial Agents and Chemotherapy 44 (1) (2000) 103.

10. A. Mahmoudi and M. Iseman, JAMA 270 (1993) 65.

11. A. Valim, M. Rossetti, M. Ribeiro, A. Zaha, Journal of Clinical Microbiology 38 (8) (2000) 3119.

12. L. Yuen, D. Leslie and P. Coloe, Journal of Clinical Microbiology 37 (12) (1999) 3844.

13. S. Watterson, S. Wilson, M. Yates, F.A. Drobniewski, Journal of Clinical Microbiology 36 (7) (1998) 1969.

14. P. Riska, W. Jacobs and D. Alland, International Journal of Tuberculosis and Lung Diseases 4 (2 Suppl 1) (2000) S4.
15. B.J. Kim, S.K. Hong, K.H. Lee, Y.J. Yun, E.C. Kim, Y.G. Park, G.H. Bai and Y.H. Kook, Journal of Clinical Microbiology 42 (3) (2004) 1308.

16. L. Herrera-Leon, T. Molina, P. Saiz, J.A. SaezNieto and M.S. Jimenez, Antimicrob Agents Chemother 49 (1) (2005) 144.

17. K.S. Ko, J.M. Kim, J.W. Kim, B.Y. Jung, W. Kim, I.J. Kim and Y.H. Kook, Journal of Clinical Microbiology 41 (7) (2003) 2908.

18. C. Drosten, M. Panning and S. Kramme, Clinical Chemistry 49 (2003) 1659.

19. K.J. Edwards, L.A. Metherell, M. Yates and N.A. Saunders, Journal of Clinical Microbiology. 39 (2001) 3350.

20. S.H. Montenegro, R.H. Gilman, P. Sheen, R. Cama, L. Caviedes, T. Hopper, R. Chambers and R.A. Oberhelman, Clinical Infectious Diseases 36 (1) (2003) 16.

21. I. Mokrousov, T. Otten, B. Vyshnevskiy and O. Narvskaya, Antimicrobial Agents and Chemotherapy 47 (7) (2003) 2231.

22. L. Garcia, M. Alonso-Sanz, M.J. Rebollo, J.C. Tercero and F. Chaves, Journal of Clinical Microbiology 39 (5) (2001) 1813.

23. A. Telenti, P. Imboden, F. Marchesi, T. Schmidheini and T. Bodmer, Antimicrob. Agents Chemother 37 (1993) 2054.

24. J.H. Voeller, C.I. Truica and E.P. Gelmann, Cancer Research 58 (1998) 2520.

25. Anonymous, PPM DOTS in Indonesia; A strategy for action, WHO, Geneva, Switzerland (2003).

26. H. Lee, R. Johnson, H.E. Bang, A.M. Jordaan, L. Dar, B.K. Khan, T.C. Victor and S.N. Cho, World Journal of Nuclear Medicine 5 (4) (2006) 241.

27. F.R. Cockerill, Antimicrob. Agents Chemother 43 (2) (1999) 199.

28. M. Ieven and $H$. Goossens, Clinical Microbiology Review 10 (1997) 242.

29. B. Boddinghaus, T. Rogall, T. Flohr, H. Blocker and E.C. Bottger, Journal of Clinical Microbiology 28 (1990) 1751.

30. J.E. Clarridge, R.M. Shawar, T.M. Shinnick and B.B. Plikaytis, Journal of Clinical Microbiology 31 (1993) 2049.

31. S. Ehlers, M. Pirmann, W. Zaki and H. Hahn, Eur. Journal of Clinical Microbiology, Infect. Dis. 13 (1994) 827. 
32. K.D. Eisenach, M.D. Cave, D. Sifford, J.H. Bates and J.T. Crawford, Am. Rev. Respir. Dis. 144 (1991) 1160.

33. F.J. Jenkins, PCR Methods and Applications 3 (1994) S77.

34. T. Bodmer, G. Zurcher, P. Imboden and A. Telenti, Journal of Antimicrobial Chemotherapy 35 (1995) 345.

35. A. Telenti, P. Imboden, F. Marchesi, D. Lowrie, S. Cole, M.J. Colston, L. Matter, K. Schopfer and T. Bodmer, Lancet 341 (1993) 647.

36. H. Ohno, H. Koga, S. Kohno, T. Tashiro and K. Hara, Antimicrob. Agents Chemother. 40 (1996) 1053.
37. B.J. Kim, S.H. Lee, M.A. Lyu, S.J. Kim, G.H Bai, S.J. Kim, G.T. Chae, E.C. Kim, C.Y. Cha and Y.H. Kook, Journal of Clinical Microbiology 37 (1999) 1714.

38. K. Hirano, C. Abe and M. Takahashi, Journal of Clinical Microbiology 37 (8) (1999) 2663.

39. S. Maeda, M. Matsuoka, N. Nakata, M. Kai, Y. Maeda, K. Hashimoto, H. Kikura, K. Kobayashi and Y. Kashiwabara, Antimicrob. Agents Chemother. 45 (12) (2001) 3635.

40. K. Hayashi, Genet. Anal. Biomol. 9 (1992) 73.

41. K. Hayashi and D.W. Yandell, Human Mutation 2 (1993) 404. 
